\title{
NATURE OF THE RELATIONSHIP BETWEEN STRATEGIC LEADERSHIP, Operational Strategy and Organisational Performance
}

\author{
Kobus Serfontein
}

PSG Konsult, Cape Town

Johan Hough

Department of Business Management, University of Stellenbosch

Accepted: September 2011

Since the mid-1980s a growing body of leadership research has focused on strategic leadership, in contrast to managerial and visionary leadership. It focused on how top leadership makes decisions in the short term that guarantees the long-term viability of the organisation. The best performing organisations are consciously strategic in their leadership planning. These top leaders also have the ability to align human resources in an effective way directly to the business strategy. This article identifies some of the direct and indirect pathways in which strategic leadership influences the operational strategy and performance of business organisations in South Africa. This research pinpointed theoretical and substantively meaningful endogenous organisational capabilities that mediated this relationship and exogenous organisational factors that moderated this relationship.

Key words: strategic leadership, operational strategy, organisational performance

\section{1}

\section{Introduction}

Wheeler, McFarland \& Kleiner (2008:1) argue that:

A rapidly changing world has created a society craving for speed and action. Future leaders, therefore, face incredible pressures to deliver immediate results, to do more with less and to manage an ever-increasing personal workload. The pace and urgency of daily demands can make it difficult to be more than the step ahead into the future. But in a world of changing conditions and priorities, leaders and individual contributors alike must be able to look beyond the 'now' and take a more strategic leadership approach to their work and responsibilities.

Without effective strategic leadership, the probability that an organisation can achieve superior, or even satisfactory, performance when confronting the challenges of the global economy will be greatly reduced (Hitt \& Ireland, 1999).

What, then, is strategic leadership? Wheeler, McFarland \& Kleiner (2008:1) have explained it as follows:

It is nothing more than the ability to anticipate, prepare and get positioned for the future. It is also the ability to mobilise and focus resources and energy on the factors that make a difference and will position one for success in the future. It is the courage to think deeply about what one wants to do. Applied strategic leadership is about creativity, intuition and planning to help one reach one's destiny.

Great leaders are judged as much by what they leave behind as by what they achieve during their tenure. A vibrant, vital organisation that is fiercely competitive and driven to excel is, of course, an important legacy for a leader (Boal \& Hooijberg, 2001). This means having in place a high-performing ${ }^{1}$ team, a thinking 
organisation and managers and employees at all levels passionately committed to getting things done. In this context, this study identifies the direct and indirect pathways to strategic leadership practices from the literature, with an empirical survey of the top 200 listed South African organisations of 2008 in order to ascertain how these antecedents influence the success of these organisations.

\section{2}

\section{Importance of the research}

The importance of improving economic growth and international competitiveness, and building South Africa's capacity to implement high performing strategic leadership practices was discussed in the introduction. Government, the private and public sectors view the capacity to implement strategic leadership as a crucial initiative towards the future success of South Africa. However, because of various complexities, business organisations in South Africa find it particularly difficult to implement strategic leadership practices (see Human Capital Management, 2005/6).

On a practical level, business leaders need guidelines to identify and overcome obstacles that stand in the way of strategic leadership practices. The stratified systems theory of Jacobs and Jaques (1987) classifies the performance requirements for leaders in organisations as direct, general and strategic. Distinct elements define the leadership environment within each level. Unmistakable differences among the three levels include complexity, time horizons and focus (see Guillot, 2003).

Most leaders spend their careers leading at the direct or tactical level. In this environment, the leader interacts directly with the same people every day by maintaining a direct span of control. The time horizon is very short normally less than one year. At the direct level of leadership, communications generally occur with the same organisation and focus exclusively on the internal audience. Because business leaders spend more time at this level than any other, it becomes familiar and comfortable (Guillot, 2003). Some business leaders however, will mature and move to the general or operational level, where performance requirements begin to change. From the perspective of budding strategic leaders, performance requirements for the strategic level change the most and are least familiar. It is important for those leaders to use integrative thinking as the challenges are great, the stakes are high and the performance requirements are stringent. It is therefore very important to convince South African business leaders to use their integrative thinking to comply with the stringent performance requirements in our business organisations and country.

The impetus and importance for the research can be divided into three main areas:

- The importance of building organisations' capability to implement high performance strategic leadership practices.

- The practical value thereof to business leaders in South Africa.

- The lack of research in South Africa on the impact of strategic leadership on the operational strategy and performance of South African business organisations.

\section{3}

\section{Literature review/Background}

Few leaders allow themselves to think about strategy and the future. Leaders should give direction to every part of the organisation from the corporate office to the loading dock. Strategic leadership is therefore the ability of the leaders to create and recreate reasons for the organisation's continued existence. The leader must have the ability to keep one eye on how the organisation is currently adding value and the other eye on changes, both inside and outside the organisation, that either threaten its position or present some new opportunity for adding value (Montgomery, 2008).

\subsection{Explaining strategic leadership}

Rowe (2001:82) defined strategic leadership as: 'The ability to influence others to voluntarily make day-to-day decisions that enhance the long-term viability of the organisation, while at the same time maintaining its short-term financial stability.' Amos (2007:3) has a similar view to Rowe and defines strategic leadership as: 'The ability to 
understand the entire organisation and the environments within which they operate and using this understanding to create strategic change through other people so as to position the organisation in the environment for both short-term stability and long-term viability.'

Hitt, Ireland and Hoskisson (2007) conceptualise strategic leadership as the ability to anticipate, envision, maintain flexibility and empower employees to create strategic change as necessary. Boal \& Hooijberg (2001) take an individual competence level focus. They suggested that effective strategic leaders must create and maintain absorptive and adaptive capacity in addition to obtaining managerial wisdom. Absorptive capacity involves the ability to learn by recognising new information, assimilating it and applying it in a disciplined manner. Adaptive capacity involves the ability to change due to variations and conditions.

\subsection{Operational strategy and the impact of strategic leadership on the strategy of an organisation}

The primary task of high performance leaders is to provide strategic direction to the organisation, various departments and divisions within the organisation, and to the people who ultimately implement strategic leadership. People at 'the top' of the organisation, normally in executive leadership positions, have tended to control over strategic processes. They have tended to make decisions, crate policies, and inform people who report to them about the tasks and objectives that must be fulfilled. In essence, they have exercised 'power over others' as the main means of getting things done. In the process they have often become alienated from the realities of operational demands and challenges.

To compete, survive and perform in a highly competitive environment, an organisation's strategy must be aligned with that of its environment and at the same time the organisation must have the capabilities that fit its strategy. This is to say that 'fit' (see Beer, Voelpel, Leibold \& Tekie, 2005) must be achieved within the organisation as well as with the business environment. To accomplish this alignment, leaders have to be open to learning about how their decisions and behaviours fit the environment, strategy and organisation. This suggests that effective leaders enable their organisations to confront the tensions that prevent alignment and, through a collaborative process, reshape alignment at several levels: between environment and strategy, strategy and organisation, organisation and the leadership team, and between key people (Porter, 2008).

Many organisations deploy the latest approaches to organisational efficiency in hopes of achieving fit, but too often find that they are unable to reap the full benefits from such activities (Baden-Fuller \& Stopford, 1994). One of the main reasons for this is the lack of an integrated approach that changes multiple dimensions of the organisational system, particularly key organisational capabilities and leadership behaviour.

Porter (2008) confirms the viewpoints above, stating that understanding the forces that shape industry competition is the starting point for developing strategy. Every organisation should already know what the average profitability of its industry is and how it has changed over time. Most importantly, an understanding of industry structure guides leaders towards fruitful possibilities for strategic action, which may include any or all of the following: positioning the organisation to cope better with competitive forces; anticipating and exploiting shifts in the forces; and shaping the balance of forces to create a new industry that is more favourable to the organisation. The best strategies exploit more than one of these possibilities (Porter, 2008).

As the best practices and new competencies start to become entrenched, the organisation and its people become increasingly ready to make a quantum shift that is capable of transforming the organisation. This is the step where it becomes possible to expect and demand the wide-spread execution of strategic leadership and competitiveness practices, and to require leaders across all levels to live the values that accompany this shift. In change leadership terms, it is the time when it is both possible and desirable to increase the pressure to practice the strategic leadership requirements (Rowe, 2001). 
By this stage all policies and procedures, as well as practices that contribute to organisational development and culture, should be aligned to the shift towards good strategic leadership practices (see Figure 1).

\section{Figure 1}

Organisational performance and managerial, visionary and strategic leadership

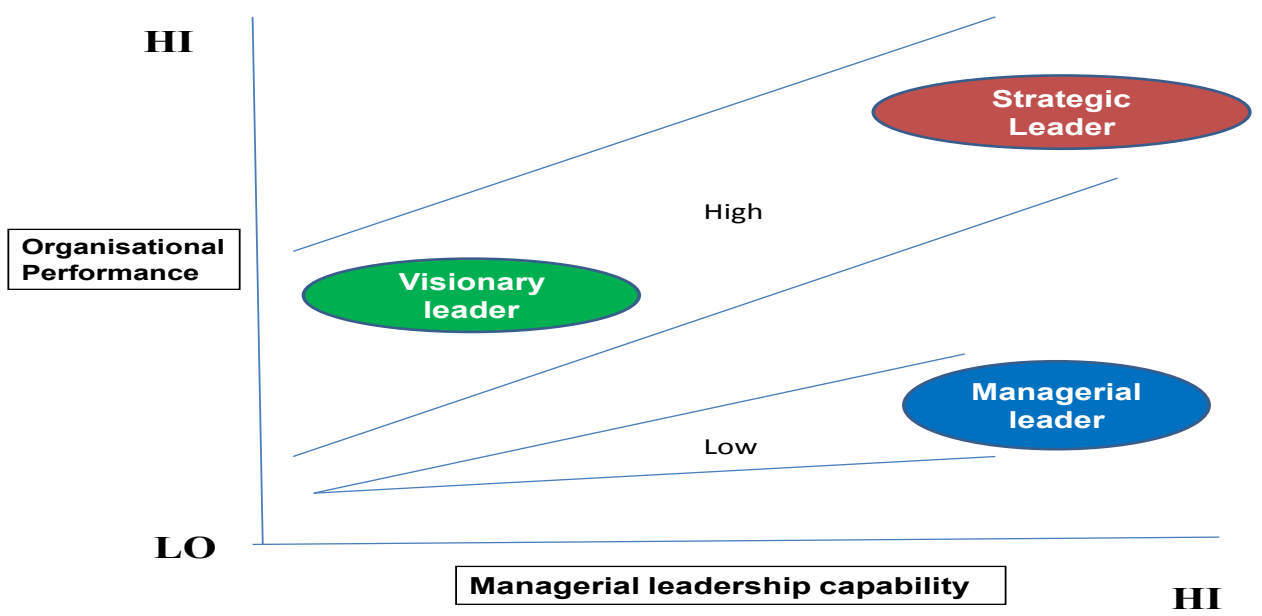

Source: Rowe (2001:84)

Montgomery (2008) further stated that it is the responsibility of the executive leadership to formulate a challenging view of the future, providing the organisation with a clear idea of where threats could come from and how the organisation is positioning itself to cope with them. Having some certainty, amidst the uncertainty of the future, is crucial. While endless scanning and assessing of all factors cannot pre-empt future threats completely, all employees in the organisation have to know that there is a plan to cope with some eventualities.

\subsection{The leader's responsibility for the implementation of strategy}

In the past, strategy execution tended to be top down; in future, strategy execution rests with everyone. The 'what' of strategy will always come top down, so it is the execution that is different in future organisations. Organisations can all go about their business brainstorming and creating something they call strategy, but the institutional capacities and capabilities of driving it through onto ground level is a totally different challenge. Leadership fluctuates. In the past leadership was clear - they knew who the leader was and who the followers were. In future, the leader sometimes needs to be a follower. Collins (2005:9) has brilliantly put it forward that: 'We cannot see something from the perspective of another if we do not have deep humility, because without it we impose our own perspective or analyse things from our own perspective only; we will not see the other person's viewpoint.' What this means is that the leaders of an organisation need to readdress their role in terms of practices and power. Organisations need to consider whether their leaders recognise, appreciate and embrace their power (Nel \& Beudeker, 2009).

\subsection{Organisational performance}

Many organisations can appear to be high performers in the short run - by riding favourable market conditions, for example, or by being fortunate with a single product or market position - only to decline quickly when business conditions turn against them.

To be a true high performer, an organisation must survive and thrive across economic and market disruptions. To measure the 
performance of organisations, it is important not to only use a single measurement, but to use different dimensions. Breene and Nunes (2006) proposed, after many years of qualitative and quantitative research towards the performance of organisations, that the following five dimensions (critical success factors) can be used as measurement, grading each on a curve against competitors in a carefully considered peer set:

- Growth - as measured by revenue expansion.

- Profitability - as measured by the spread between the return on assets and cost of capital.

- Positioning for the future - as represented by the position of share price that cannot be explained by current earnings and by the position of the industry total each organisation's future value represents.

- Longevity - as measured by the duration of out-performance in total return to shareholders.

- Consistency - as measured by the number of years out of seven the peer set median in profitability, growth and positioning for the future was beaten.

The role of leadership is of fundamental importance to the performance and success of organisations. This includes many aspects like visionary, motivator, enabler, facilitator as well as mentor and coach. Its importance has been identified in the work of Fawn and Leavy (see Breene \& Nunes, 2006). Their research aimed to establish the portfolio of attributes exhibited by leaders in two groups of organisations. The attributes with the highest ranking are those which are intuitive and require exceptional leadership skills. They are direction, vision, selection of key personnel, people motivation and communication.

The leader must also understand the critical interplay between capabilities and value creation, a relationship that goes to the heart of high performance in business organisations (Breen \& Nunes, 2006). To create value, each high-performing organisation develops a formula for doing business - either at the enterprise or business unit level - that successfully translates a big idea regarding customer needs into a unique set of connected business processes and resources that costeffectively satisfy those needs. Innovation and talent management are also two of the essential capabilities needed for high performance in a business organisation. The investment in training and leadership development to enhance innovation and the development of talent has been observed as a crucial strategic focus in high-performing business organisations (Nel \& Beudeker, 2009).

Every high performing business organisation also has a high performance culture. If you spend any amount of time with leaders and employees of a high-performance business organisation, you will get an almost palpable sense of the organisation as a distinctive community. Nel and Beudeker (2009:12) call this a 'village of leaders' as a unique way to approach the core and common business elements related to culture, leadership and workforce. A culture of performance embodies an organisation's unique approach to managing those elements common to every organisation, and is therefore crucial to long-term effectiveness, the quality and speed of decision making and the mastery of change and innovation.

So how do organisations harness this to optimise performance? Nel \& Beudeker (2009) suggest that:

They have developed an integrated framework that is specifically engineered to achieve optimal performance. Although each of the frameworks can be used as a standalone tool, it is only when they are used in conjunction with one another that organisations will truly be able to achieve the type of turn-around required to take them to worldclass status.

There is, however, a practical challenge that an organisation will have to consider at all times. This study provides insights into the best operating practices that sustainably competetive organisations have entrenched through many years of exquisite effort and focused leadership. It is impossible to achieve success with one great leap and there is no evidence at all of any organisation that has ever achieved world class performance in a short period. 
4

\section{Research methodology}

\subsection{Hypotheses}

Against the backdrop of the literature review provided, it is expected that operational strategy and organisational performance will be influenced by strategic leadership practices. Strategic leadership can, therefore, be viewed as a competency, that is, creating capabilities within an organisation by the acquisition, recombination and renewal of these activities and resources (Eisenhardt \& Martin, 2000; Miller, Eisenstat, \& Foote, 2002). Following from the above, these two hypotheses were tested:

H1: Strategic leadership is directly and positively associated with operational strategy.

H2: Strategic leadership is directly and positively associated with organisational performance.

The purpose of this quantitative study was to determine how strategic leadership is associated with operational strategy and organisational performance in business organisations in South Africa.

\subsection{Survey and sample}

A cross-sectional survey design consisting of two phases was used: a pilot study to test the measuring instrument and the administration of a telephone survey. The results of the pilot study determined the refinement of the questionnaire. The telephone survey was conducted by an independent organisation from January to March 2009.

The sample selected for this study consisted of the 200 top-performing organisations that were part of the Financial Mail survey of 2008. The organisations represent all major industry groups. Financial and industry performance information has been used from the 2008 Financial Mail survey.

In this survey, the performance of these organisations was measured over a five-year period to ensure consistency in their performance. The respondents in the survey were the chief executive officer (CEO) or a member of the senior executive group. Their responsibilities in their organisations give them a unique and comprehensive view of strategic leadership activities.

All 200 top performing organisations in South Africa for 2008, as published in the Financial Mail survey, were part of the sample. A total of 118 valid responses were received, or a response rate of 59 percent. Data was captured electronically during the interview.

\subsection{Measurement instrument}

A measurement instrument was developed to measure the impact of strategic leadership on operational strategy and organisational performance. Items of existing measurement instruments were combined, expanded, adapted or reduced as required to achieve the goals of the study, taking the prerequisites of validity and reliability into account. The measurement instrument needed to measure:

- Strategic leadership (independent variable)

$$
\begin{aligned}
& \text { - Action } \\
& \text { - Coherence } \\
& \text { - Discipline }
\end{aligned}
$$

- Strategy orientation (dependent variable)

- Strategy creation and formulation

- Strategy execution

- Operational excellence (dependent variable)

- Cost management

- Product differentiation

Integration

- Organisational performance (dependent variable)

- ROA (return on assets)

$$
\text { - EPS (earnings per share) }
$$

- Self-reported performance

To measure strategy orientation in the sample companies the two scales of strategy creation and strategy execution were used based on Treacy and Wiersema's (1995) strategy model. Organisations were asked: 'To what extent do the following statements best describe your workplace's competitive strategy?'

Porter (1996) argues that operational excellence can be seen as a particular type of cost-management positioning. He also states that organisations can only attain a competitive advantage and earn superior returns if they pursue a dedicated positioning strategy. Treacy and Wiersema (1995) include more than cost- 
management as operational effectiveness. They refer to practices that allow a company to better utilise its inputs by developing better products faster and reducing defects in products. The effective integration of functional areas is a key factor for operational effectiveness and offers different advantages in successful management of industry change (Kaplan \& Norton, 2004).

Organisational performance was measured using the two financially based measurements of ROA en EPS, as published in the Financial Mail (2009) survey, listing the 200 top performers in South Africa in 2008. In addition to financial measures, self-reported performance measures were used in this study. Organisations were asked to indicate their current level of performance relative to their competitors for each of the six performance measures.

These performance measures were adaptive leadership, autonomy, communication, processes and systems, knowledge and values. These were enhanced by questions formulated by the researcher and based on the literature to ensure that each variable in the measuring instrument was represented by at least three items.

\subsection{Cronbach Alpha coefficients}

Cronbach Alpha coefficients were computed and used to assess the internal consistency of the measuring instrument on responses obtained from the pilot study. The estimated Cronbach Alpha coefficients for the independent variable of the strategic leadership constructs of action, coherence and discipline were $0.77,0.76$ and 0.75 respectively. The Cronbach alpha coefficients of the dependent variables of strategy orientation were 0.76 and 0.66 respectively. With regards to the dependent variable of operational excellence, the Cronbach Alphas were 0.71, 0.87 and 0.72. All the researched coefficients would appear to satify Nunnally's (1978) suggested minimum criterion for internal reliability.

The data were analysed by using the Statistica (Stratsoft, 2008) programme. Exploratory data analysis (EDA) was used to assess individual variables, and descriptive statistics - such as means and standard deviations - were used to describe the data. Additionally, inferential statistics were employed to determine the relationships between the constructs of strategic leadership and operational strategy as well as organisational performance.

\section{5}

\section{Results}

Corporate characteristics and a descriptive analysis are presented in this section. The profile of the sample is discussed in terms of two characteristics: annual turnover and the size of the organisation. Thereafter a comparative analysis of the specific dimensions will be discussed.

\subsection{Corporate characteristics of respondents}

The corporate characteristics of the respondents are discussed in terms of the two variables: number of employees and annual turnover.

As seen from Figure 2, the largest proportional category was organisations with 1-1000 employees, which represented 38.3 percent of the respondents. The majority of the organisations $(72.61 \%)$ had a staff complement of between 1 and 5000 employees. The study also revealed that the majority of the organisations $(67.57 \%)$ reported a turnover of between 1 and 15 billion rands. 


\section{Figure 2}

Number of employees and annual turnover
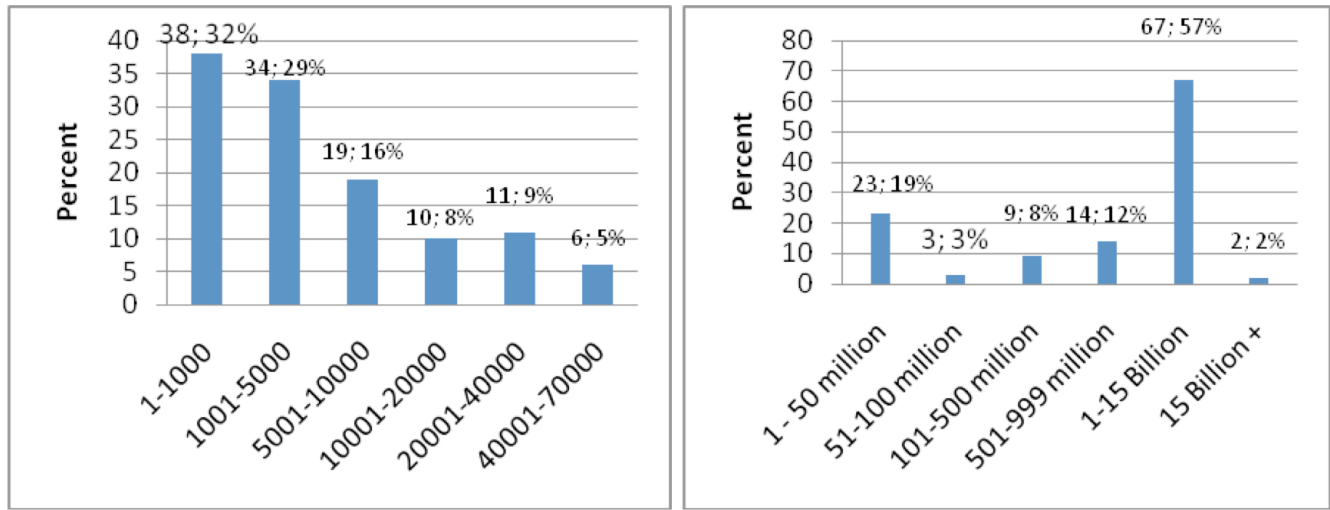

\subsection{Descriptive analysis of the dimensions}

A descriptive analysis of the dimensions was conducted as part of the exploratory approach to analysis of data. A profile of the respondents participating in the study is shown in Table 1, using mean, standard deviation and Cronbach Alpha.

The respondents answered all the questions pertaining to strategic leadership, operational strategy and organisational performance. All the questions were measured on a nine-point scale. The mean of strategic leadership (action, coherence and discipline) constructs were calculated from both the operational strategy and organisational performance constructs. The standard deviation shows how the observations are spread around the mean.

\section{Table 1}

Descriptive statistics of constructs

$$
\mathrm{N}=118
$$

\begin{tabular}{|l|l|l|l|}
\hline \multicolumn{1}{|c|}{ Dimension } & $\begin{array}{c}\text { Min/Max } \\
\text { values }\end{array}$ & Mean (sd) & $\begin{array}{c}\text { Cronbach } \\
\text { alpha }\end{array}$ \\
\hline Strategic leadership & \multicolumn{2}{|c|}{} & 0.77 \\
\hline Action & $4 / 36$ & $27.07(4.14)$ & 0.76 \\
\hline Coherence & $3 / 27$ & $21.72(3.42)$ & 0.75 \\
\hline Discipline & $5 / 45$ & $35.40(5.02)$ & \\
\hline Operational strategy & & & 0.76 \\
\hline Creation and formulation of strategy & $3 / 27$ & $19.54(3.89)$ & 0.66 \\
\hline Execution of strategy & $3 / 27$ & $20.42(3.11)$ & \\
\hline Organisational performance & & & 0.71 \\
\hline Cost management & $3 / 27$ & $21.31(3.08)$ & 0.87 \\
\hline Product differentiation & $4 / 36$ & $28.23(4.43)$ & 0.72 \\
\hline Integration & $4 / 36$ & $26.74(4.11)$ & 0.72 \\
\hline Adaptive leadership & $3 / 27$ & $20.67(3.33)$ & 0.72 \\
\hline Autonomy & $3 / 27$ & $21.52(3.04)$ & 0.90 \\
\hline Communication & $3 / 27$ & $19.00(4.12)$ & 0.72 \\
\hline Process \& systems & $4 / 36$ & $28.24(3.88)$ & 0.77 \\
\hline Values & $3 / 27$ & $22.41(3.25)$ & 0.43 \\
\hline Knowledge & $3 / 27$ & $21.18(2.88)$ & \\
\hline
\end{tabular}




\subsection{Comparative analysis}

In this section the aim is to determine whether certain key variables are significantly associated, and furthermore whether certain sub-groups are significantly different. Correlations among certain variables were calculated and the p-values were used to determine whether the differences among the constructs were significant. The focus is on the following specific dimensions:
- Strategic leadership and operational strategy

- Strategic leadership and organisational performance

Figure 3 illustrates the influence of strategic leadership re-conceptualised as three interrelated constructs of action, coherence and discipline as exogenous constructs (Serfontein, 2010:223-225).

Figure 3

An illustration of the conceptual correlation model of strategic leadership, strategy orientation, operational excellence and organisational performance

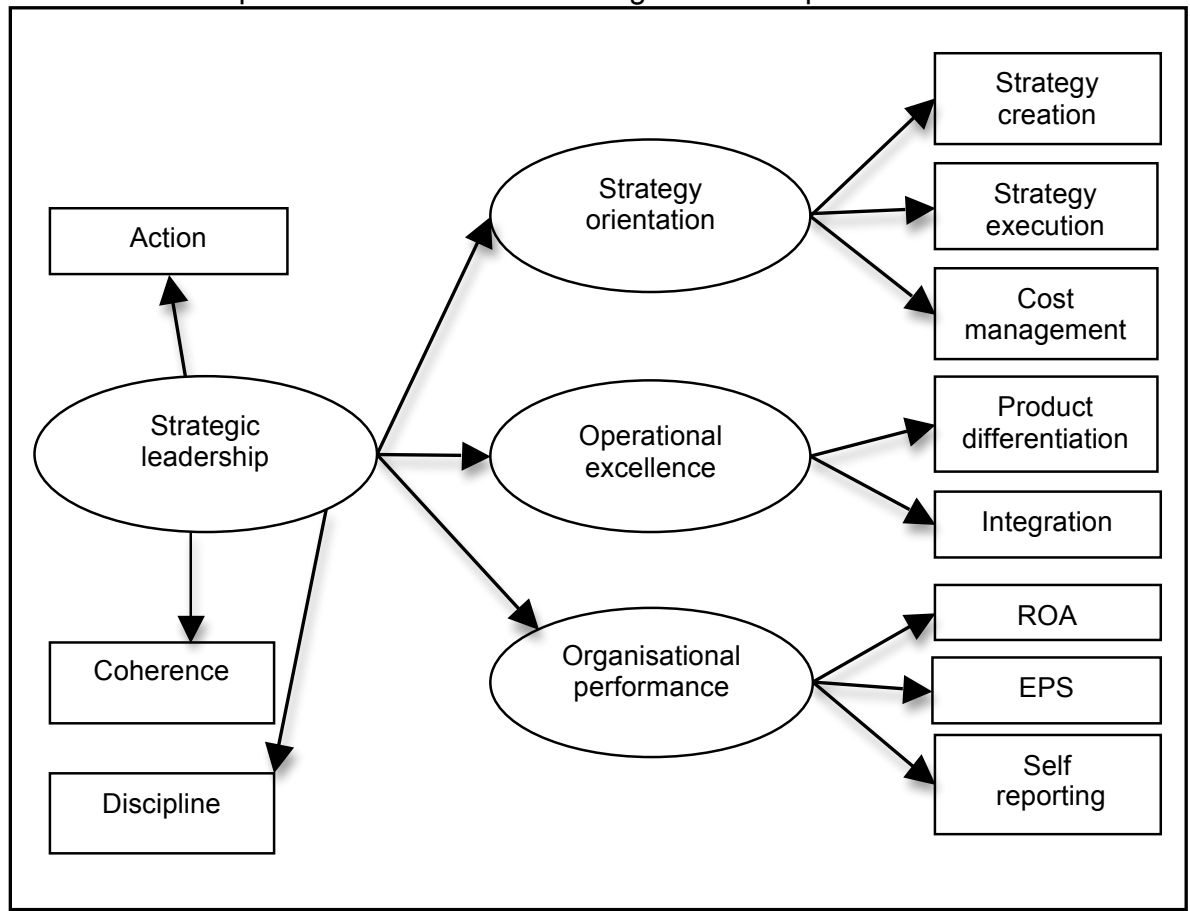

Endogenous constructs of strategy orientation, operational excellence and organisational performance are also displayed. Strategy orientation is measured by the ability to create a strategy as well as to execute the strategy effectively. Operational excellence is measured by cost management, product differentiation and integration. Finally, organisational performance is measured by ROA, EPS and selfreported measurements.

As discussed in this study, strategic leadership literature highlights these characteristics as having an impact on the operational strategy and performance of business organisations.

\subsubsection{The influence of strategic leadership on operational strategy}

Theoretically speaking, the three constructs of strategic leadership (action, coherence and discipline) should exert a strong effect on strategy orientation and its dimensions. These relationships were examined by means of correlation analysis.

The results of the correlation analysis are shown in Table 2. The Spearman correlation coefficients $(\rho)$ and p-values of the separated 
dimensions of strategy orientation are shown with the strategic leadership constructs. Saunders et al. (1997:321) remark that a correlation of +0.3 indicates a weak positive correlation and +0.7 a strong positive correlation.

Table 2

A summary of the correlation analysis ( $r$ ) and $p$-values as well as the Spearman correlation coefficient comparing the dimensions of strategy orientation with the constructs of strategic leadership $(\mathrm{N}=118)$

\begin{tabular}{|l|c|c|c|c|}
\hline \multicolumn{1}{|c|}{ Dimensions of strategy orientation } & $\begin{array}{c}\text { Correlation } \\
\text { analysis (r) }\end{array}$ & $\begin{array}{c}\text { Correlation } \\
\text { analysis (P-value) }\end{array}$ & $\begin{array}{c}\text { Spearman } \\
\text { correlation (p) }\end{array}$ & $\begin{array}{c}\text { Spearman } \\
\text { correlation (p-value) }\end{array}$ \\
\hline Action versus Execution of strategy & 0.71 & 0.0000 & 0.64 & 0.00 \\
\hline Coherence versus Creation of strategy & 0.76 & 0.0000 & 0.74 & 0.00 \\
\hline Coherence versus Execution of strategy & 0.76 & 0.0000 & 0.68 & 0.00 \\
\hline Discipline versus Creation of strategy & 0.62 & 0.0000 & 0.62 & 0.00 \\
\hline
\end{tabular}

a) Action versus execution of strategy

The data from the study shows a strong positive relationship between action and the execution of strategy $(r=0.71 ; p=0.0000)$. The Spearman correlation coefficient also indicates the same relationship $(\rho=0.64$; $\mathrm{p}=0.00)$.

As indicated earlier, Hitt, Ireland and Hoskisson (2007) defined action as the component of strategic leadership that determines strategic direction and exploits core compe- tencies. These aspects are both crucial in the process to execute the strategy of the organisation. If the organisation does not have a strategy and people do not have the necessary competencies it will be impossible to effectively execute the strategy. As discussed above, this study has confirmed a strong, positive relationship $(r=0.71)$ in the sample organisations between action and the execution of the strategy, which is indicative of the theory discussed in this study.

\subsubsection{The influence of strategic leadership on organisational performance}

\section{Table 3}

A summary of the correlation analysis $(r)$ and $p$-values as well as the Spearman correlation coefficient, comparing the dimensions of self-reported organisational performance with the constructs of strategic leadership $(n=188)$

\begin{tabular}{|l|c|c|c|c|}
\hline \multicolumn{1}{|c|}{$\begin{array}{c}\text { Dimensions of organisational } \\
\text { performance }\end{array}$} & $\begin{array}{c}\text { Correlation } \\
\text { analysis (r) }\end{array}$ & $\begin{array}{c}\text { Correlation } \\
\text { analysis (p-value) }\end{array}$ & $\begin{array}{c}\text { Spearman } \\
\text { correlation (p) }\end{array}$ & $\begin{array}{c}\text { Spearman correlation } \\
(\mathbf{p} \text {-value) }\end{array}$ \\
\hline Action versus adaptive leadership & 0.69 & 0.0000 & 0.65 & 0.00 \\
\hline Action versus processes and systems & 0.67 & 0.0000 & 0.58 & 0.00 \\
\hline Action versus knowledge & 0.58 & 0.0000 & 0.48 & 0.00 \\
\hline Coherence versus autonomy & 0.72 & 0.0000 & 0.66 & 0.00 \\
\hline Coherence versus communication & 0.69 & 0.0000 & 0.69 & 0.00 \\
\hline Coherence versus knowledge & 0.69 & 0.0000 & 0.66 & 0.00 \\
\hline Discipline versus adaptive leadership & 0.69 & 0.0000 & 0.64 & 0.00 \\
\hline Discipline versus processes and systems & 0.61 & 0.0000 & 0.53 & 0.00 \\
\hline Discipline versus values & 0.65 & 0.0000 & 0.57 & 0.00 \\
\hline
\end{tabular}

The second hypothesis in this study is that strategic leadership (action, coherence and discipline) is directly and positively associated with organisational performance. Strategic leadership should, therefore, also have a positive effect on organisational performance and its dimensions. These relationships were examined in this study by means of correlation analysis and Spearman's correlation coefficient.

The results of the correlation analysis on the relationship between strategic leadership and organisational performance are shown in Table 2. The Spearman correlation coefficients and p-values of the separated dimensions of organisational performance are shown with the 
strategic leadership constructs. Saunders et al. (1997:321) remark that a correlation of +0.3 indicates a weak positive correlation and +0.7 a strong positive correlation.

a) Action versus adaptive leadership, processes and systems and knowledge

The data from the study showed a strong positive relationship existed between action and adaptive leadership $(\mathrm{r}=0.69 ; \mathrm{p}=0.0000)$; action and processes and systems $(\mathrm{r}=0.67 ; \mathrm{p}=$ $0.0000)$ as well as action and knowledge $(\mathrm{r}=$ $0.58 ; \mathrm{p}=0.0000)$. The Spearman correlation coefficient indicates an equally strong relationship $(\rho=0.65 ; p=0.00)$ towards action and adaptive leadership; action and processes and systems $(\rho=0.67 ; p=0.00)$ as well as action and knowledge $(\rho=0.67 ; p=0.00)$.

Based on the Cronbach Alphas, the correlation analysis as shown in Tables 2 and 3 , both hypotheses one and two can be assessed. Null hypothesis one and two (H01 and H02) contends that no relationship exists between strategic leadership and operational strategy orientation as well as strategic leadership and organisational performance. The alternative hypothesis (HA1 and HA2) is, therefore, that a positive relationship exists between strategic leadership and operational strategy as well as between strategic leadership and organisational performance. This study has indicated there is a strong, positive statistically significant relationship between strategic leadership and operational strategy. There is also a positive relationship between strategic leadership and organisational performance. Based on these findings, the hypothesis is rejected. By implication, the literature and the respondents who participated in this study confirmed that strategic leadership is directly and positively associated with the operational strategy and organisational performance in business organisations in South Africa.

The empirical research done in this study supplemented the theory surrounding strategic leadership by suggesting that if leadership in organisations formulate and execute their strategies effectively, this strategic competitiveness will give them an advantage to survive in a turbulent and uncertain economy. It also suggested that if organisations manage their costs effectively and focus on product differentiation and the integration of their people, they will perform well and yield above-average returns.

\section{6}

\section{Discussion of results}

The discussion of results in this section will focus on the relationship between strategic leadership and operational strategy as well as the relationship between strategic leadership and organisational performance.

\subsection{The relationship between strategic leadership and operational strategy}

As mentioned in this study, operational strategy includes strategic (directional) orientation and operational excellence of the organisation. The relationship between strategic leadership and strategy orientation was found to be statistically significant as the dimensions of strategic leadership (action, coherence and discipline) all measured between 0.62 and 0.76 with p-values of 0.0000 as indicated by the correlation analysis. The Spearman coefficient correlation analysis confirmed this relationship ( $\rho=$ between 0.62 and $0.74 ; p$-values of 0.00 ).

The creation and formulation of a compelling strategy is extremely important for any business organisation as it determines the future direction of the organisation as well as exploits the core competencies of the employees. In this study it was also confirmed that organisations need to develop their human capital in order to perform according to the new goals and direction (Serfontein, 2010: 223). The respondents in the study also confirmed the importance of establishing effective strategic controls and to sustain a corporate culture that emphasises ethical practices (Serfontein, 2010:223).

According to Stewart (2007) the sobering fact is that less than 10 percent of strategies effectively formulated are effectively implemented. The execution of the strategy is, therefore, critically important. In this study the very important relationship between strategic leadership and the execution of the strategy was confirmed by the respondents. Through this, the sample organisations acknowledged that they need to establish strategic controls to 
make sure that the strategy is effectively executed. There also needs to be a corporate culture that all the employees understand the strategy and also know what their role is to make the strategy work.

This study confirmed the relationship between strategic leadership and operational excellence in business organisations in South Africa as the results of the correlation analysis showed strong positive relationships between strategic leadership and cost management as well as strategic leadership (hypothesis 1). The study did, however, reveal a weak positive relationship between strategic leadership and product differentiation. The price-leader position seems to be a danger as it can quickly become a commodity seller position, which leads to a lower ROA. This is consistent with Porter's (1996) contention that operational effectiveness is not strategy. Therefore operational excellence is best seen as a basis, and perhaps a prerequisite, for the growthorientated strategies of product leadership and integration of the functional areas of the organisation.

Cost management has always been one of the major challenges in business organisations and it has a direct and indirect impact on the operational effectiveness of the organisation. Even if the organisation has an acceptable or high turnover and it does not have the ability to manage and control the costs, the organisation will find it very difficult to survive. This is even more applicable in the current turbulent environment where the global economy is heading towards a recession. The strong positive relationship between strategic leadership and cost management was confirmed in this study.

Finally, it was confirmed in this study that leadership must have the discipline to create a culture and environment where all people and departments in the organisation have the ability to integrate their competencies, initiatives and skills.

\subsection{The relationship between strategic leadership and organisational performance}

The literature in this study asserted that highperformance strategic leadership practices will help organisations to enhance their performance while competing in changing environments. The literature was empirically confirmed in South African business organisations with the correlation analysis done in this study on the relationships between strategic leadership constructs and selfreported organisational performance dimensions. All the constructs of strategic leadership and self-reported organisational performance measured a strong, positive statistically significant relationship.

Adaptive leadership showed a positive association with strategic leadership, which confirms the importance of leaders engaging in adaptive work by providing direction, and protects the employees by managing the rate of change (Serfontein, 2010:225). The respondents also confirmed the importance of the leaders' ability to orient people to their new roles and responsibilities. The leader should also help the people in the organisation to maintain those norms.

Autonomy, also referred to as work discretion, showed the strongest significant relationship with strategic leadership of all the self-reported performance dimensions. This means that the leadership's ability and discipline to permit employees to make decisions about performing their work in a way they believe is most effective is extremely important. This is even more challenging in a diverse South African business environment, where strategic leaders of the sample organisations confirmed the importance of this relationship.

The data from this study confirmed the statistically significant and strong relationship between strategic leadership and effective processes and systems in the organisation. The literature in this study suggested that the business is a complex, adaptive system populated by purposeful, interdependent people. The leadership, therefore, needs to understand the whole system in the organisation as one system concept in an organisation contains the others. The study suggested that it is therefore, no longer just the products that are important, it is the process that is important.

The Cronbach alpha for communication was measured as the highest in the study at 
0.90, which confirms the reliability of this construct. The importance of good communication in business organisations was suggested by the literature and confirmed by this study for business organisations in South Africa. In order to perform, people at all levels need to be informed as all planning processes are, at the core, vehicles for communication.

The literature in this study found that the category of values is especially relevant not just for top-level executives, but for all employees. Employees need constantly to balance demands from their stakeholders, the market, because it highlights the leader's and all the people in the organisation' capability to change. The empirical data in this study confirmed this notion as values showed a consistent positive relationship with strategic leadership. The test for first-rate leaders in business organisations in South Africa is, therefore, the ability to exhibit contradictory or opposing behaviours while still maintaining some measure of integrity, credibility and direction.

\section{7 \\ Summary and conclusion}

The main contribution of this study was the assessment that strategic leadership is directly and positively associated with operational excellence and performance in business organisations in South Africa. The managerial implications of the proposed model constructed in the study are that leadership and executives in business organisations are able to implement high-performing strategic leadership practices to enhance the strategy orientation and operational excellence in their organisations.

This study also supplemented the theory surrounding strategic leadership by suggesting that if organisations formulate and execute their strategies effectively, this strategic competitiveness will give them an advantage to survive in a turbulent and uncertain new economy. It also suggested that if organisations manage their costs effectively and focus on a product differentiation and the integration of their people, they will perform well and yield above-average returns (Serfontein 2010: 225).

The study identified several avenues for further research by using different research methods and examining the impact of strategic leadership in different contexts. Future researchers should examine the impact of strategic leadership on the operational strategy and performance in different business sectors, as well as in public organizations, in order to have a holistic view of the impact of strategic leadership on the performance of organisations in South Africa with its diverse and uncertain environment.

Competition in the remainder of the $21^{\text {st }}$ century's global economy will be complex, challenging and filled with competitive opportunities and threats. This study asserts that effective strategic leadership practices could help organisations enhance their performance while competing successfully in the turbulent and unpredicted South African environment.

\section{Endnote}

1 High performance is defined as the enduring or out-performance of peers, across business and economic cycles, often across generations of leadership (Breene \& Nunes, 2006:11).

\section{References}

AMOS, T. 2007. Strategic leadership: key driver for strategic implementation. Management Today. May. BADEN-FULLER, C. \& STOPFORD, J. 1994. Rejuvenating the mature business. Boston: Harvard Business School Press.

BEER, M., VOELPEL, S.V., LEIBOLD, M. \& TEKIE, E.B. 2005. Strategic management as organisational learning: developing fit and alignment through a disciplined process. Long Range Planning Journal, 38(5).

BOAL, K.B \& HOOIJBERG, R. 2001. Strategic leadership research: moving on. Leadership Quarterly, 11(4):515-549. 
BREENE, T. \& NUNES, P.F. 2006. Going the distance: how the world's best companies achieve high performance. High performance business, 3.

COLLINS, J. 2005. Level 5 leadership: the triumph of humility and fierce resolve. Harvard Business Review, 79(1):66-76.

EISENHARDT, K.M. 1989. Making fast strategic decisions in high-velocity environments. Academy of Management Journal, 32(3):543-576.

EISENHARDT, K.M. \& MARTIN, J.A. 2000. Dynamic capabilities: what are they? Administrative Science Quarterly, 21(10-11):1105-1121.

FINANCIAL MAIL, 2009. SA's Top 200 Performers for 2008, 20 January:38.

GUILLOT, W.M. 2003. Strategic leadership: defining the challenge. Air \& Space Power Journal, Winter 2003.

HITT, M. \& IRELAND, R.D. 1999. Achieving and maintaining strategic competitiveness in the $21^{\text {st }}$ century: the role of strategic leadership. Academy of Management Executive, 13:43-57.

HITT, M.A., IRELAND, R.D \& HOSKISSON, R.E. 2007. Strategic management: competitiveness and globalization $\left(7^{\text {th }}\right.$ ed.) Mason, Ohio: Thomson/South Western.

HUMAN CAPITAL MANAGEMENT, 2005/6. Leading the dance: leadership for changing times: strategic executive report (3 ed.):21-23.

JACOBS, T.O. \& JAQUES, E. 1987. Leadership in complex systems. In J. Zeidner (ed.) Human productivity enhancement, 2:7-65. New York: Praeger.

KAPLAN, R.S. \& NORTON, D.P. 2004. Measuring the strategic readiness of intangible assets. Harvard Business Review. February:52-63.

MONTGOMERY, C.A. 2008. Putting leadership back into strategy. Harvard Business Review, 86(1):54-60.

MILLER, D., EISENSTAT, R. \& FOOTE, N. 2002. Strategy from the inside out: building capability creating organisations. California Management Review, 44(3):37-54.

NEL, C. \& BEUDEKER, N. 2009. Revolution: how to create a high performance organisation. Cape Town: The Village of Leaders Products.

NUNNALLY, J.C. 1978. Psychometric theory. New York: McGraw-Hill.

PORTER, M.E. 1996. What is strategy? Operational effectiveness is not strategy. Harvard Business Review, 74(6):61-79.

PORTER, M.E. 2008. The five competitive forces that shape strategy. Harvard Business Review, 86(1): 78-93.

ROWE, W.G. 2001. Creating wealth in organisations: the role of strategic leadership. Academy of Management Executive, 15(1):81-95.

SAUNDERS, M., LEWIS, P. \& THORNHILL, A. 1997. Research methods for business students. London: Financial Times Publishing.

SERFONTEIN, J.J. 2010. The impact of strategic leadership on the operational strategy and performance of business organisations in South Africa. University of Stellenbosch. Unpublished PhD thesis.

STATSOFT, INC 2008. STATISTICA (data analysis software system), version 7.1. www.statsoft.com. [Multimedia CD-Rom].

STEWART, R. 2007. Strategy in an uncertain future with limited control. Unpublished document. Stellenbosch: University of Stellenbosch.

TREACY, M. \& WIERSEMA, F. 1995. Discipline of market leaders: choose your customers, narrow your focus, dominate your market. London: Harper Collins Publishers.

WHEELER, S., MCFARLAND, W. \& KLEINER, A. 2007 A blueprint for strategic leadership. Resilience Report. Booz, Allen \& Hamilton in Strategy + business, 49, Winter 2007. 